GA-A16429

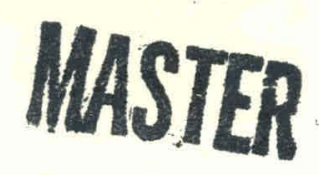

\title{
CHANGES IN NEAR-SURFACE MICROSTRUCTURE OF METALLIC LIMITERS FOLLOWING ONE YEAR OF SERVICE IN DOUBLET III
}

P. W. TRESTER, D. L. SEVIER, and M. M. SABADO 


\section{DISCLAIMER}

This report was prepared as an account of work sponsored by an agency of the United States Government. Neither the United States Government nor any agency Thereof, nor any of their employees, makes any warranty, express or implied, or assumes any legal liability or responsibility for the accuracy, completeness, or usefulness of any information, apparatus, product, or process disclosed, or represents that its use would not infringe privately owned rights. Reference herein to any specific commercial product, process, or service by trade name, trademark, manufacturer, or otherwise does not necessarily constitute or imply its endorsement, recommendation, or favoring by the United States Government or any agency thereof. The views and opinions of authors expressed herein do not necessarily state or reflect those of the United States Government or any agency thereof. 


\section{DISCLAIMER}

Portions of this document may be illegible in electronic image products. Images are produced from the best available original document. 


\section{DISCLAIMER}

This report was prepared as an account of work sponsored by an agency of the United States Government. Neither the United States Government nor any agency thereof, nor any of their employees, makes any warranty, express or implied, or assumes any legal liability or responsibility for the accuracy, completeness, or usefulness of any information, apparatus, product, or process disclosed, or represents that its use would not infringe privately owned rights. Reference herein to any specific commercial product, process, or service by trade name, trademark, manufacturer, or otherwise, does not necessarily constitute or imply its endorsement, recommendation, or favoring by the United States Government or any agency thereof. The views and opinions of authors expressed herein do not necessarily state or reflect those of the United States Government or any agency thereof. 
CHANGES IN NEAR-SURFACE MICROSTŔUCTURE OF METALLIC LIMITERS FOLLOWING ONE YEAR OF SERVICE IN DOUBLET III

P. W. Trester, D. L. Sevier, M. M. Sabado* General Atomic Company, San Diego, CA

*Ebasco Services Co., Inc., Princeton, NJ

\section{ABSTRACT}

The structural alloys Ta-10W, Mo, and Inconel $\mathrm{X}-750$ were used for plasma limiters during the 3-MW ohmic heating experiments of the Doublet III tokamak. Post-service examinations of these limiters are reviewed. Near-surface melting, cracking, and microstructural changes are shown and discussed. During DIII service, elements from other metallic components were transported by the plasma and deposited on the limiter surface; significantly, high concentrations of Ni, Fe, Mo, and $\mathrm{C}$ were detected in the regions found to be microcracked in the Ta-10W. Observations and analyses are made that are relevant to the design of limiter and armor components for larger tokamaks.

\section{INTRODUCTION :}

During the initial 3-MW ohmic heating phase of Doublet III (DIII) the limiter systems used to define the plasma boundary and to protect the vessel wall were composed of high and middle atomic number $(\mathrm{z})$ metallic elements. Two movable primary limiters were used in conjunction with many fixed, back-up limiters encircling the vessel poloidally at.specified toroidal positions and also positioned for protection of diagnostic instrumentation. The limiters were operated at an average power loading of $300 \mathrm{~W} / \mathrm{cm}^{2}$ for up to $1.0 \mathrm{sec}$, with peak power depositions of $>15 \mathrm{~kW} / \mathrm{cm}^{2}$. The mechanical design of the metallic limiter systems and their operational performance during 1978-1980 have been presented earlier [1]. Plasma experiments with the metallic primary limiters were completed as planned, and these limiters fully satisfied their mechanical design requirements. A graphite limiter and armor system is now used in DIII as a replacement for the metallic limiters in order to achieve the requirements of high power density with low $\mathrm{Z}$ (effective) impurity release [2]

Material selection for the metallic limiters included consideration of the abnormal conditions in which deposition of high localized energy occurs $[1,3]$. This energy is sufficient to melt and cause changes in the nearsurface microstructure of the limiter blade and fastener system. Such events did occur durfing DIII service and caused surface melting over extensive areas and some cracking near the surface. Major fracture or distortion was averted by choosing alloys that have both suitable mechanical properties in all microstructural conditions and tolerance for melting, surface cracking, and microstructural changes.

High-Z materials were selected for the startup limiter systems primarily because of their outstanding thermal and structural properties at high temperature $[1,3]$. Tantalum/10-wt \% tungsten alloy (Ta-10W) was used for the primary movable limiters, and Mo was used for the stationary back-up limiters. Medium-Z limiters were installed after one year of opera- tion ( $~ 5,000$ plasma shots) to reduce radiation losses from the plasma [1]. Inconel X-750, a nonmagnetic alloy, was selected because of its high strength and toughness and low content of high $\mathrm{Z}$ elements. After a year of service ( $~ 8,000$ plasma shots), the $\mathrm{X}-750$ limiters wer removed. An Inconel X-750 limiter is shown for comparison with the Ta-10W limiter in Fig. 1 .

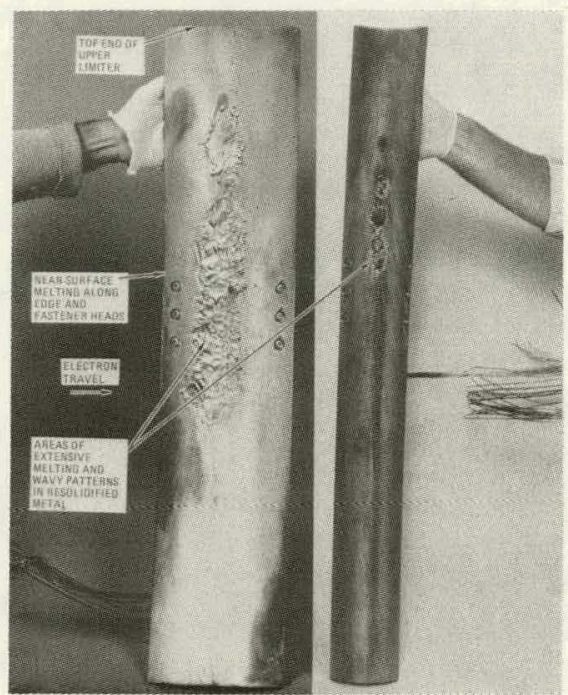

Fig. 1. Metallic primary limiters from Doublet III showing evidence of near-surface melting and erosion. (a) Inconel X750 alloy and (b) Ta-10W alloy. Limiter length is $0.92 \mathrm{~m}$

A metallurgical examination of the limiters was conducted to provide a description of the changes in surface topography and near-surface microstructure. This information is of value for assessing the continuation of bulk material integrity and for establishing a basis for extrapolation to the more severe operating conditions anticipated in future devices. The information also provides data for correlating the extent of interactions between the plasma and the limiter. 
SURFACE TOPOGRAPHY AND MICROSTRUCTURE EXAMINATIONS :

\section{Ta-10W LIMITER:}

As shown in Fig. 1, examination of the Ta-10W limiter blade revealed overlapping oval shapes of gross melting 30 to $40 \mathrm{~mm}$ long. The melting has been attributed indirectly to runaway electron discharges, since the region exhibited low-level gamma radiation, and a threshold electron energy of $\sim 10 \mathrm{MeV}$ is necessary for gamma-ray-induced transmutations [1]. No cracks were observed (at $25 \mathrm{X}$ ) from the surface of these resolidified regions. Gross melting occurred where the surface was both parallel to the magnetic field and near the elliptic axis of the doublet plasma [1]. Two sections were made through the blade, transverse to the long axis, one through the melted zone at just above the upper set of fastener holes and the other through the upper holes. The slice removed was mapped and cross sectioned further to enable metallographic examination of the microstructural features below the blade surface [4]. Figure 2 shows the microstructural change associated with the zone of severest melting, which extended to a typical depth of $0.5 \mathrm{~mm}$. Subsurface cracks and/or pores are present and are oriented parallel to the limiter surface. Similar grain features on both sides of the defects indicate the pores and cracks occurred subsequent to solidification.

Along the region receiving electron impingment at near-normal incidence (electron edge), a region of $45 \times 3 \mathrm{~cm}$ exhibited a smooth appearance, suggesting that very shallow surface melting had occurred. Tiny craters dotted this region. The rims of the fastener holes appeared eroded and a cross-sectional examination revealed intergranular microcracking as shown in Fig. 3. The widths of the cracks have been enlarged slightly by the etchant used during metallographic preparation. Similar microcracking was also observed in a cross section through a panhead type of fastener screw as shown in Fig. 4. Prior to sectioning the fastener, the surface of the screwhead was analyzed (to a depth $\sim 1 \mu \mathrm{m}$ ) using an energy dispersion X-ray system in an SEM. The surface composition was determined to be high in elements foreign to the Ta-10W alloy. The results were, in weight percent: $\mathrm{Mo}-0.62, \mathrm{Fe}-$ $0.29, \mathrm{Ni}-0.20$, and $\mathrm{Cr}-0.07$, with $\mathrm{Ta}-90.5$ and W-8.3. Further, as indicated in Fig. 4, measurement of $\mathrm{Ni}, \mathrm{Fe}, \mathrm{Mo}, \mathrm{C}$, and $\mathrm{Cr}$ concentration was made using an electron microprobe. A profile was mapped from the screwhead surface downward (parallel to the screw axis) at $10-\mu \mathrm{m}$ increments for a distance of $1500 \mu \mathrm{m}$. The beam diameter was $5 \mu \mathrm{m}$, and during analysis the beam was scanned laterally over a distance of $50 \mu \mathrm{m}$ at each location of analysis. Many grains were crossed, since this screw exhibited a structure of narrow elongated grains. The relative concentration values are plotted in Fig. 5. No gradients or increase in concentration values were found deeper than 200 $\mu \mathrm{m}$. The sensitivity for detecting $\mathrm{Cr}$ was $0.03 \%$; for oxygen it was $0.5 \%$ and for $C$ it was $0.05 \%$. Carbon was in high concentration to about the same depth as the numerous small cracks that extended inward from the screwhead surface. Nickel and iron were distributed inward for about $200 \mu \mathrm{m}$. The presence of these elements and their distribution resulted from implantation and diffusion during DIII service. The stock Ta-10W rod was certified as less than $5 \mathrm{ppm}$ each for $\mathrm{Ni}, \mathrm{Fe}$, and $\mathrm{Cr}$. The material specification AMS 7848 sets limits of $<0.03$ wt \% Mo and carbon at $<0.005$ wt \%

The ductility and toughness properties of refractory metals are decreased with even moderately low concentrations of interstitial elements such as hydrogen, carbon, and oxygen or by alloying with $\mathrm{Ni}, \mathrm{Fe}$, or $\mathrm{Cr}$. These elements were present in the DIII plasma environment. $\mathrm{Ni}, \mathrm{Fe}$, and $\mathrm{Cr}$ have very low solubility in either $\mathrm{Ta}$ and $\mathrm{W}$ and would tend to form embrittling intermetallic compounds that also

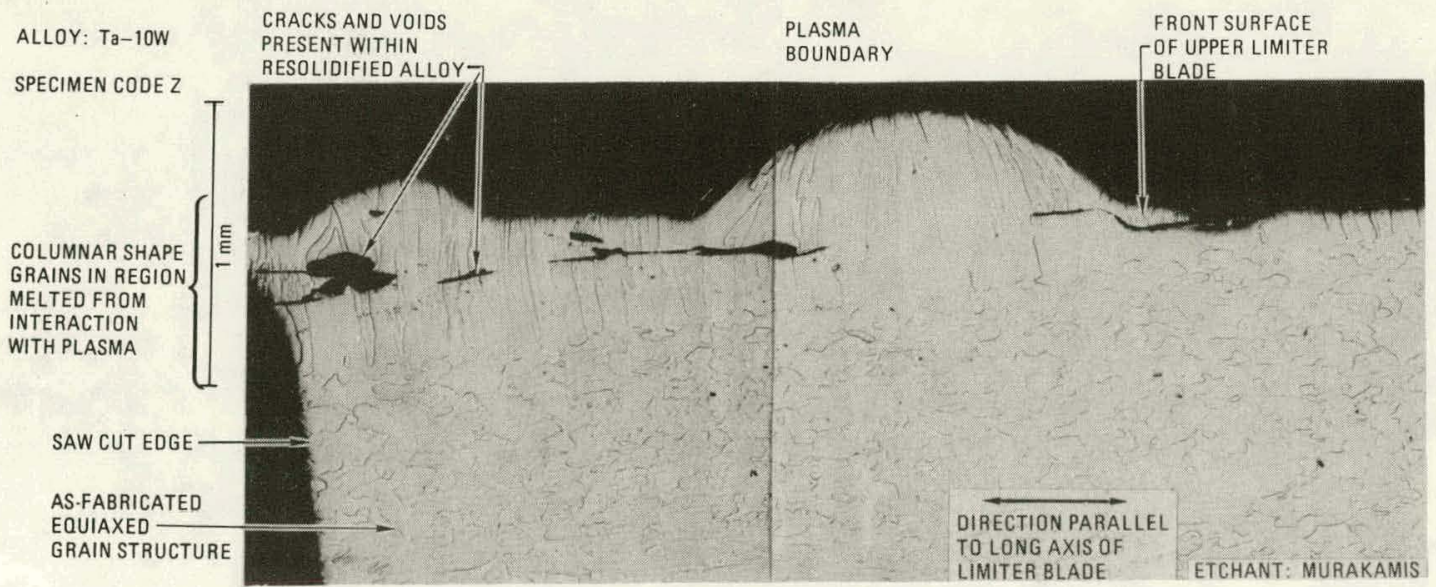

Fig. 2. View of cross section thrnigh gross melted zone on uppes, primary 1 imiter of Doublet III 


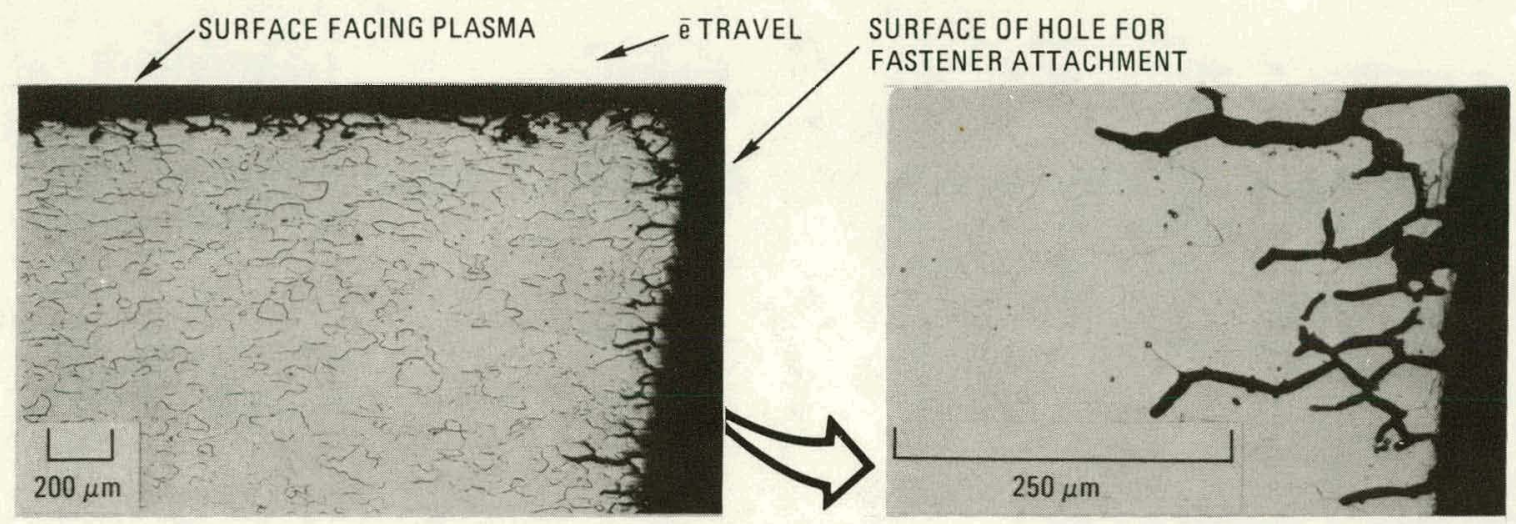

Fig. 3. Cross section showing near-surface intergranular cracking in the Ta-10W alloy due to interaction with plasma of Doublet III. Etchant: $\mathrm{H} \mathrm{NO}{ }_{3}-\mathrm{HF}-\mathrm{H}_{2} \mathrm{O}$ (10:5:2 by volume)

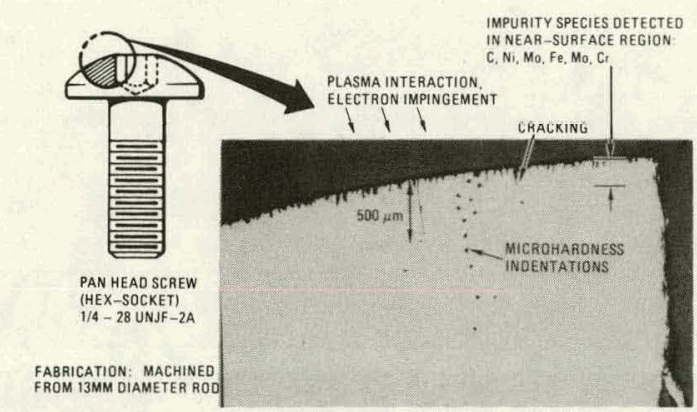

Fig. 4. Cross-sectional view of fastener from primary limiter of Doublet III showing surface cracking and region of microanalyses. Electron microprobe X-ray measurements were in zone between deepest crack and hardness indentations

have lower melting points than Ta-10W (mp $3047^{\circ} \mathrm{C}$ ). Diffusion along grain boundaries would be preferred sites. The Tokamak wall and diagnostic instrumentation covers were made of Inconel 625 or stainless steel 316 and are the sources for the foreign elements found in the Ta-10W. The high thermal loading at the limiter surface causes stress conditions which can induce cracking in the near-surface region of the alloyed Ta-10W. No cracking was observed, however, below the affected areas shown in Figs. 3 and 4. Similarly, in areas of the limiter where there was no change in surface texture, no microcracking was observed in cross sections examined. The microcracking observed in Fig. 4 was also observer chararteristically in fasteners used on the ion side. All the fastener heads experienced gross, radial cracking during attempted removal with a hexagonal-shaped key wrench.

\section{Mo Limiters:}

On some of the Mo limiters, which were positioned on the inner wall of the plasma chamber, noticeable melting occurred along the

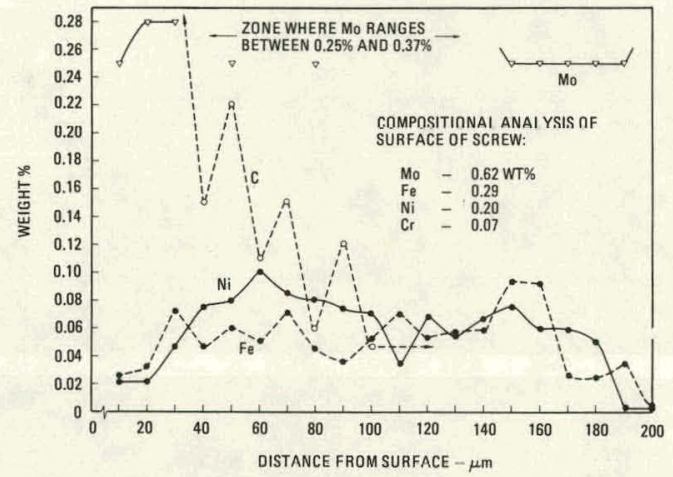

Fig. 5. Concentration gradients for foreign species implanted and diffused below surface of a Ta-10W fastener

edges at both ends of the part as shown in Fig. 6. A cross section was made through an edge-melted region parallel to the long axis of the limiter. Below melted zones a nearby surface microstructure had been recrystallized. The recrystallized or as-cast microstructural condition for molybdenum, in contrast to the preferred stress-relieved wrought structure, has very low toughness and ductility at room temperature. Thus, the molybdenum becomes more vulnerable to crack initiation and propagation in these regions of microstructural change. As a result, one Mo limiter exhibited a long surface crack, $95 \mathrm{~mm} \times 1.24 \mathrm{~mm}$ deep, which resided in the microstructural conditions described. No Mo limiters were fractured in DIII service.

The largest isolated melted region observed (Fig. 6) on a Mo limiter was $20 \mathrm{~mm}$ in diameter and $0.7 \mathrm{~mm}$ deep as shown in Fig. 7. A recrystallized zone $1.2 \mathrm{~mm}$ deep was observed below the melted material. A sizable recrystallized zone of equiaxed grains was always observed between the columnar grain structure of the melted zone and the elongated, wrought grain structure of the Mo bar stock used. 
In contrast to the du11, sputtered appearance on the ion side of the Mo limiters, the electron side of the limiter shown in Fig. 6 exhibited a smoothed but textured surface of many small bumps and craters. A low magnification view of this surface is presented in Fig. 8. A cross section was cut through the region marked A-A and examined at higher magnification as shown in the accompanying photomicrograph. The craters and bumps (surface upheaval) were revealed clearly. At the bottom of the crater were two cracks, each at an angle to the direction of depression. On the specimen examined, this undulating pattern repeated approximately every 5 to $20 \mu \mathrm{m}$ along the surface. The narrow white layer on the surface of the crater is a layer of $\mathrm{Ni}$ added to assist metallographic preparation.

INCONEL X-750 LIMITER:

Extensive melting ( $\mathrm{mp} \sim 1400^{\circ} \mathrm{C}$ ) was observed on many of the Inconel $\mathrm{X}-750$ back-up limiters that were located on the inner wall. An example is shown in Fig. 9. A pattern of recessed regions parallel to the limiter length was characteristic of the melted region on the electron side. Adjacent to these receded zones was a layered buildup of metal. Also present was a zone of melting which formed a rippled pattern. Each ripple was oriented at between $10^{\circ}$ to $30^{\circ}$ off vertical. Cracks were observed at the base of the ripples and are indicative of solidification shrinkage cracks which can form at temperatures just below the melting point. A section oriented as shown in Fig. 9 was cut through the limiter (and fastener hole) and examined. The sectional view is shown in Fig. 10. Cracks extended from the surface through the melted zones and the adjacent heat-affected zone. Crack depths of $\leqslant 0.67 \mathrm{~mm}$ were observed. The deepest of the receded regions extended $4.0 \mathrm{~mm}$ below the original surface of the limiter. The adjacent buildup of metal was $1.8 \mathrm{~mm}$ outward from the original surface. The limiters of this design weighed $675 \mathrm{~g}$ and exhibited no change ( $\pm 1 \mathrm{~g}$ ) after DIII service despite the appreciable melting and metal flow.

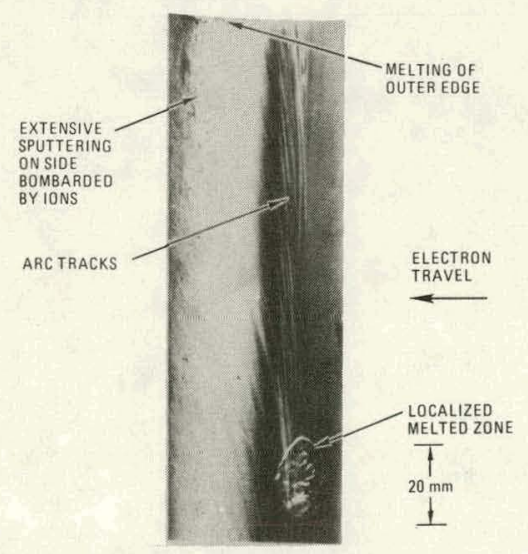

Fig. 6. Front view of surface of a Mo backup limiter

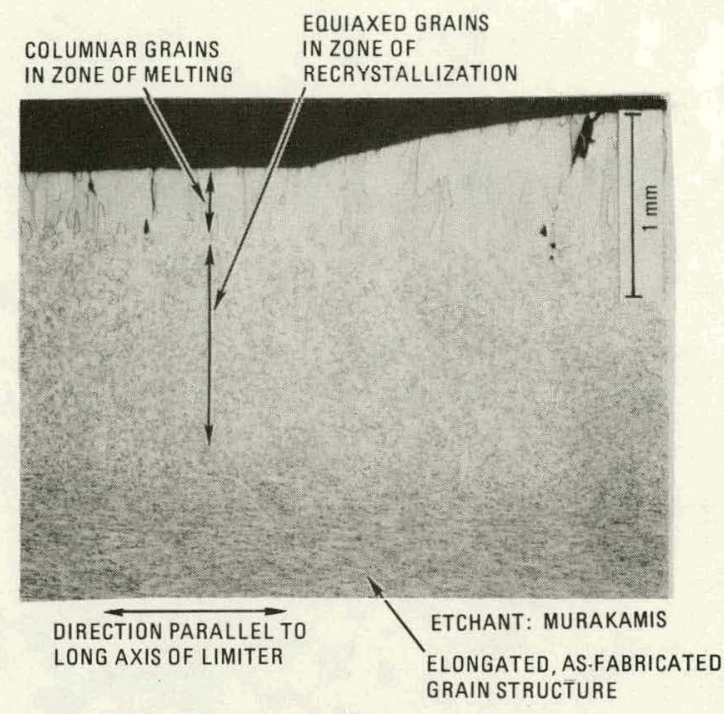

Fig. 7. Microstructure changes associated with largest melted zone observed on a Mo backup limiter

Microhardness was measured, starting from one of the melted peaks (Fig. 10) and proceeding inward radially across the limiter thickness as indicated in Fig. 11. The corresponding DPH hardness values are plotted against depth. The hardness for the precipitation heattreated condition of the limiter is reached at a shallow depth of only $1.1 \mathrm{~mm}$. Alloy $\mathrm{X}-750$ would be expected to over-age rapidly at $>850^{\circ} \mathrm{C}$ and would show a corresponding decrease in hardness. This observation of quick hardness recovery to initial hardness indicates the bulk of the 11miter maintained temperatures below the design limit of $750^{\circ} \mathrm{C}$ (max).

The primary limiter of Inconel X-750 shown in Fig. 1 after one year of service was at the same location in DIII as the Ta-10W limiter that is also shown. Noticeable features on the $\mathrm{X}-750$ limiter surface were the areas of melting, small localized cracks in some of the melted areas, arc tracks, and sputtering. No cross sections or microscopic studies were performed. Both the rims of the fastener holes and the fastener head suffered appreciable melting. In comparison with the Ta-10W, the extent of surface melting and cracking on the $i$ on and electron sides of the Inconel $1 \mathrm{im}$ iter surface appeared to be greater. The sides of the adapter supporting the limiter blade exhibited extensive melting. The characteristic features of the melted regions observed on the Inconel X-750 limiters are similar to descriptions reported for the PLT 1imiters made of AISI 304 stainless steel [5].

The central region exhibiting gross melting (many overlapping oval-shaped melted regions) from runaway electrons did not exhibit (at 10X) surface cracks. An activation of $\sim 1$ mil$1 \mathrm{irem} / \mathrm{hr}$ was measured in this central melted 


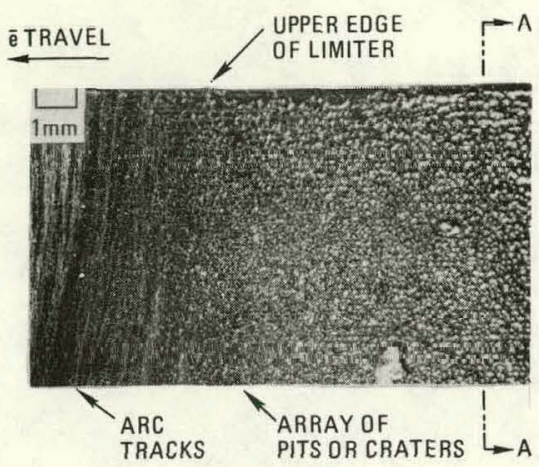

VIEW A-A

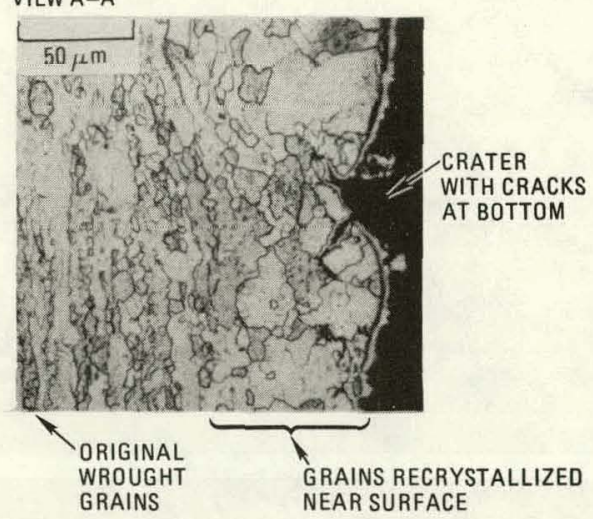

Fig. 8. Near-surface changes in microstructure of Mo backup limiter due to impingement of high energy electrons and high temperature

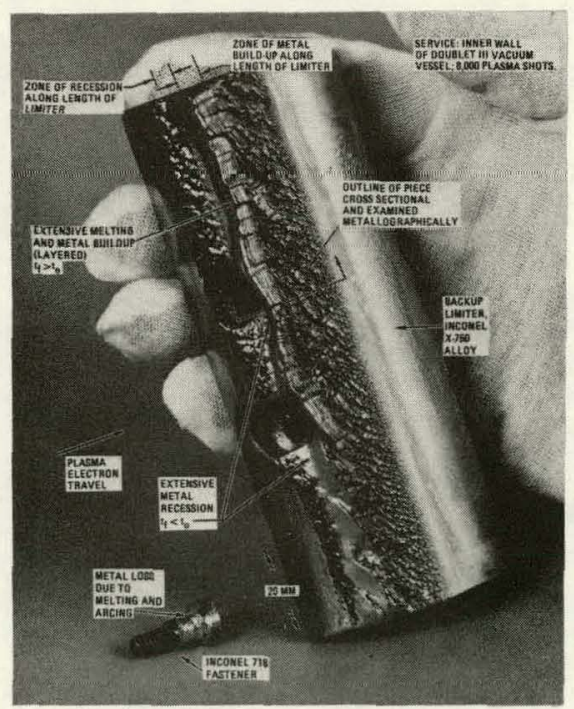

Fig. 9. Topographical changes due to melting and flow of near-surface metal on limiter from inner wa11 of Doublet III



Fig. 10. View of cross section (see Fig. 9) showing depth of melting, flow, and cracks on an Incone1 X-750 1imiter from inner wall of Doublet III

zone. Activation was attributed to gammaneutron-type transmutations during bombardment by electrons and this required energy levels $>4 \mathrm{MeV}$. Gamma-ray spectral analysis of smal.1 fragments of melted metal removed from the limiter in this region revealed that $\mathrm{Co}-57$ was the dominant isotope and was measured to be $0.035 \mu \mathrm{C} / \mathrm{g}$. The other isotopes detected are presented in Table 1 .

TABLE 1 (a)

ISOTOPES IDENTTFIED IN ACTIVATED SURFACE METAL FROM CENTRAL REGION ON THE INCONEL X-750 PRIMARY LIMITER OF DOUBLET III

\begin{tabular}{c|c|r}
\hline Nuclide & $\begin{array}{c}\text { Average Radiation } \\
\text { Level }(\mu \mathrm{C} / \mathrm{g})\end{array}$ & \multicolumn{1}{|c}{$\begin{array}{c}\text { Isotope } \\
\text { Half-LIfe }\end{array}$} \\
\hline $\mathrm{Sc}-46$ & $5.216 \times 10^{-5}$ & 83.84 days \\
$\mathrm{Cr}-51$ & $4.035 \times 10^{-3}$ & 27.80 days \\
Mn-54 & $7.784 \times 10^{-5}$ & 312.50 days \\
Co-56 & $3.121 \times 10^{-4}$ & 11.28 days \\
Co-57 & $3.553 \times 10^{-2}$ & 269.91 days \\
Co-60 & $2.382 \times 10^{-5}$ & 5.26 years \\
\hline
\end{tabular}

(a) Nominal composition of alloy Inconel $\mathrm{X}-750$ is $\mathrm{N} 1,15.5 \% \mathrm{Cr}, 7.0 \% \mathrm{Fe}$, $2.5 \% \mathrm{Ti}, 1.0 \%(\mathrm{Ta}+\mathrm{Nb}), 0.8 \% \mathrm{Co}, 0.7 \%$ Al, $0.8 \% \mathrm{Mn}, 0.4 \% \mathrm{Si}, 0.06 \% \mathrm{C}$ (wt \%).

DISCUSSION

Appropriate selection of metallic alloys has produced limiters for DIII which have demonstrated structural reliability despite the occurrence of melting and cracking on the surface. Sufficiently high ductility, toughness, and resistance to crack growth are characteristics of the Ta-10W and Inconel X-750 (below the affected, near-surface regions) that enabled the 1 imiters to meet structural performance requirements both in normal operation and during the high, localized thermal loads from disruptions and runaway electrons. 
The latter conditions raise concern with structures of brittle ceramic and/or graphite substrates and thin refractory coatings. Future tokamaks will have large amounts of stored energy available during a disruption, and the material capabilities that will become increasingly important for structural integrity during absorption of the energy are (1) capability for incurring localized deformation in all microstructural formations, (2) tolerance for or resistance to alloying at the surface, and (3) resistance to propagation of surface cracks. In addition, for the longer pulse tokamaks, erosion of the limiter surface will also be a major design concern, both because of the need to minimize impurity release into the plasma and because of the need to have a reasonable design life for limiter surface. Appropriate consideration of these factors may then dictate a design compromise that reconsiders the use of the higher $-\mathrm{Z}$ metallic materials for limiters.
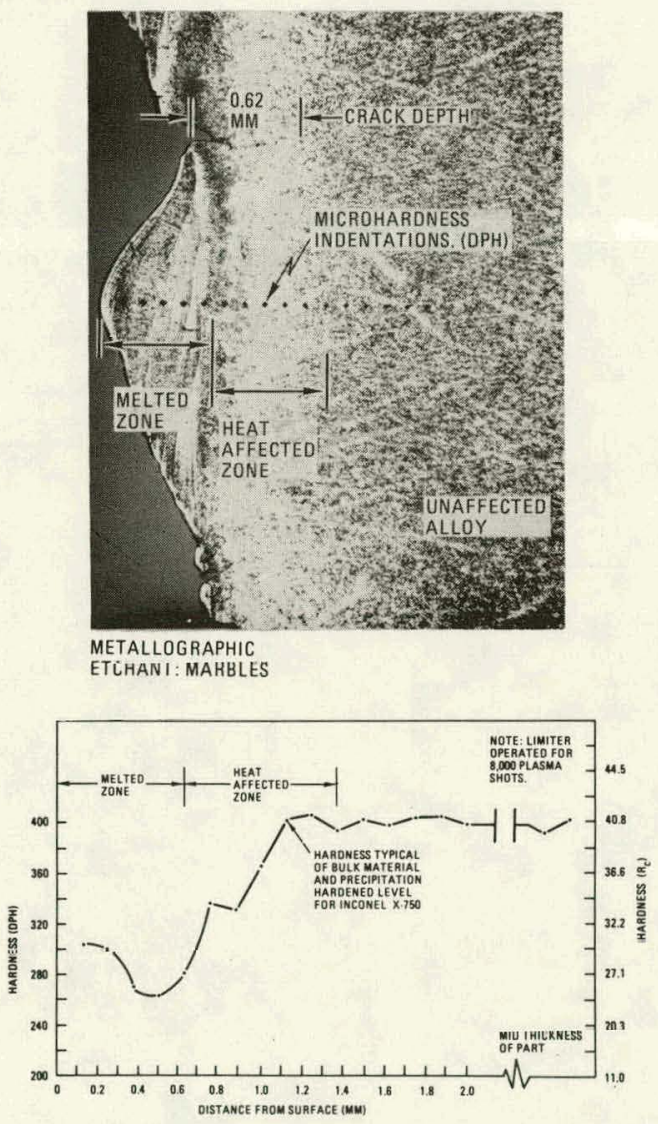

Fig. 11. Traverse of microhardness on cross section (see Fig. 10) made through severely melted zone of an Inconel X-750 back-up limiter from inner wa11 of Doublct III
SUMMARY :

Post-service metallurgical examinations have been conducted on the metallic limiters used during the 3-MW ohmic heating phase of Doublet III during 1978-1980. The limiters functioned according to structural design predictions and did not incur measurable gross deformation or major cracking. Near-surface alloying, annealing, and microcracking were prevalent. The metallurgical changes that occurred are discussed with regard to the structural integrity of limiters. The operational history and performance of the Doublet III metallic 1imiters are relevant for future limiter design in large tokamaks such as TFTR, JET, and FED.

\section{ACKNOWLEDGEMENTS :}

Appreciation is extended to N. B. Elsner for helpful discussions on degradation phenomena in refractory metals, to D. W. Hill for the gamma-ray spectral analysis and to J. E. Knipping for assistance in the metallographic analyses.

This work was supported by U. S. Department of Energy contract DE-AT03-76ET51011.

\section{REFERENCES :}

[1] Sabado, M., Marcus, F., Trester, P. W., Wesley, J., "Doublet III Limiter Performance and the Implications of Mechanical Design and Material Selection for Future Limiters," in Proceedings of the $8 \mathrm{th}$ Symposium on Engineering Problems of Fusion Research, Vol. 1, San Francisco, California, November 13-16, 1979.

[2] Sevier, D. L., et a1., "Performance of TiC-Coated Graphite in Electron Beam Tests and Doublet III Operation," paper presented at this conference.

[3] Trester, P. W., Sabado, M. M., and Elsner, M. B., "Selection of Materials for Limiters of Doublet III," Proceedings of the IEEE 7 th Symposium on Engineering Problems of Fusion Research, Knoxville, Tennessee, 1977.

[4] Hopkins, G. R., et al., "Activity Cooled Limiter for Doublet III," General Atomic Report GA-A16181, November 1980.

[5] Cohen, S. A., et al., "Mechanisms Responsible for Topographical Changes in PLT Stainless Steel and Graphite Iifmiters," Plasma Physics Laboratory Report PPPL-1671, Princeton University, Princeton, New .Tersey, June 1980.

$$
* * *
$$

